\title{
COnE)-(OES
}

CIÊNCIA E TECNOLOGIA

\section{OS RESULTADOS DO ENADE 2012, 2015 E 2018 PARA OS CURSOS DE DIREITO SITUADOS NO ESTADO DO CEARÁ}

\author{
Karyne Machado de Araujo, Edgar Marçal de Barros Filho, \\ FRANCISCO HERBERT LIMA VASCONCELOS \\ Universidade Federal do Ceará - UFC \\ <karyne.machadodearaujo@gmail.com>.<edgar@virtual.ufc.br>.<herbert@virtual.ufc.br> \\ 10.21439/conexoes.v15i0.2116
}

\begin{abstract}
Resumo. A partir da década de 1990 houve um crescimento significativo na quantidade de cursos superiores no Brasil, em especial, pela ampliação de ofertas no setor privado. Este acréscimo trouxe a preocupação com a qualidade do ensino ofertada. Foi instituído o Sistema Nacional de Avaliação da Educação Superior (SINAES) no ano de 2004. Em 2018, o Brasil totalizava 1.502 cursos de bacharelado em Direito. Em 1995 eram apenas 235 cursos, o que representou um aumento de 539\% entre os anos de 1995 e 2018. Dessa feita, o presente estudo exploratório, documental e qualitativo tem como objetivo apresentar os resultados da Avaliação de Desempenho dos Estudantes (ENADE) dos anos de 2012, 2015 e 2018 para os cursos de Direito do estado do Ceará, assim como, o estudo comparado quanto aos resultados da região Nordeste e ao consolidado nacional.
\end{abstract}

Palavras-chaves: ENADE 2012. ENADE 2015. ENADE 2018. Cursos de Direito. IES Cearenses.

\section{THE RESULTS OF ENADE 2012, 2015 E 2018 FOR LAW COURSES LOCATED IN THE ESTATE OF CEARÁ}

\begin{abstract}
Since the 1990s, there has been a significant increase in the number of higher education courses in Brazil, especially due to the expansion of offers in the private sector. This increase brought the concern with the quality of the education offered. The National Higher Education Assessment System (SINAES) was instituted in 2004. In 2018, Brazil had a total of 1,502 law degree courses. In 1995 there were only 235 courses, which represented an increase of 539\% between the years 1995 and 2018. On this occasion, the present exploratory, documentary and qualitative study aims to present the results of the Student Performance Assessment (ENADE) of the years 2012, 2015 and 2018 for the law courses in the state of Ceará, as well as the compared study regarding the results of the Northeast region and the national consolidated.
\end{abstract}

Keywords: ENADE 2012. ENADE 2015. ENADE 2018. Law Courses. Ceará IES.

\section{INTRODUÇÃO}

A partir dos idos de 1990 houve um crescimento significativo na quantidade de cursos superiores no Brasil, em especial, pela ampliação de ofertas no setor privado (BARREYRO 2006). Esta expansão trouxe a preocupação com a qualidade do ensino ofertada e, consequentemente, a necessidade de definição de uma sistemática de avaliação das instituições. O atual Sistema Nacional de Avaliação da Educação Superior (SINAES) foi instituído pela Lei ${ }^{\circ} 10.861 / 2004$, após ampla discussão no Ministério da Educação (MEC), fórum de reitores e pró-reitores, academia, parlamento e a sociedade em geral, segundo Silva e Gomes (2011). O SINAES substituiu os modelos anteriores de avaliação, a saber, PAIUB (Programa de Avaliação Institucional das Universidades Brasileiras) e ENEC (Exame Nacional de Cursos), também conhecido como Provão. O SINAES abandonou a abordagem meramente reguladora do antigo sistema, ENEC, fortemente alinhado às questões mercadológicas e para os quais o ensino superior era uma mercadoria. Implementou uma avaliação formativa, pautada no compromisso com a formação cidadã dos estudantes, baseada em qualidades éticas e em consonância com as competências profissionais demandadas pelo mercado profissional (SOBRINHO, 2010). Constitui-se uma relevante política educacional para avaliação, aprimoramento e regulação dos cursos superiores de todo Brasil. 
O SINAES é composto por três processos avaliativos quais sejam: a Avaliação das Instituições de Educação Superior (AVALIES), Avaliação dos Cursos de Graduação (ACG) e Avaliação do Desempenho dos Estudantes (ENADE). O ENADE é aplicado com alunos concluintes de curso superior, no último ano da graduação. É composto por prova com questões de formação geral, comum a todos cursos da mesma área, e por questões específicas inerentes ao curso examinado. Assim como, compreende Questionário do Estudante para identificação do perfil socioeconômico dos acadêmicos e Questionário de Percepção da Prova. A partir do resultado do ENADE é gerado o Conceito Enade e diversos indicadores para análise da qualidade das IES e dos cursos. Os resultados também são utilizados, pelo Ministério da Educação, nos processos regulatórios do ensino superior.

Por outra perspectiva, ressalte-se que o Brasil é o país com maior número de faculdades de Direito no mundo. Em 2018, o Brasil totalizava 1.502 cursos de bacharelado na área, segundo censo do Instituto Nacional de Estudos e Pesquisas Educacionais Anísio Teixeira (INEP). Em 1995 eram apenas 235 cursos de Direito o que representou um aumento de 539\% entre os anos de 1995 e 2018. No Estado do Ceará, observouse um aumento gradual na quantidade de acadêmicos em Direito inscritos para a realização do ENADE 2012, 2015 e 2018. Em especial, do ano de 2015 para o ano de 2018, o número de graduandos na área jurídica alistados para a prova aumentou de 3760 para 4679 , num incremento de aproximadamente $24,44 \%$, (INEP 2018a).

Desta feita, diante das fundamentações e considerações apresentadas, o presente estudo tem como objetivo apresentar os resultados da Avaliação do Desempenho dos Estudantes (ENADE) referente aos últimos triênios de avaliação dos cursos da área de Humanas, ou seja, os anos de 2012, 2015 e 2018, para as graduações de Direito do estado do Ceará. Assim como, evidenciar o comparativo dos resultados cearenses em relação à região Nordeste e ao acumulado nacional. Os resultados da análise foram obtidos a partir da consolidação dos documentos publicados pelo INEP, através do sítio eletrônico do instituto, referentes ao ENADE aplicado nos anos de 2012, 2015 e 2018.

Este trabalho está dividido em seis seções. A primeira é composta por esta introdução. O segundo tópico é a fundamentação teórica dos temas aqui tratados, em especial, a apresentação das características e dos objetivos da política educacional SINAES, de cada uma das suas avaliações, com destaque para o ENADE. O terceiro tópico apresentará a metodologia utilizada na construção do presente estudo. A quarta sessão enun- ciará os resultados do ENADE de 2012, 2015 e 2018 para os cursos de Direito localizados no estado do Ceará e os estudos comparados. O quinto tópico abordará as considerações finais do presente estudo.

\subsection{OBJETIVO GERAL}

Analisar os resultados do ENADE dos cursos de Direito cearenses e compará-los ao desempenho da Região Nordeste e do Brasil para compreensão do posicionamento das graduações locais frente ao desempenho regional e brasileiro nas provas do ENADE 2012,2015 e 2018 .

\subsection{OBJETIVOS ESPECÍFICOS}

a) Apresentar o conceito ENADE dos cursos de Direito cearenses para o ENADE 2012,2015 e 2018.

b) Comparar a média do Resultado Geral (RG), a média da Formação Geral (FG) e a média do Conhecimento Específico (CE) dos cursos de Direito cearenses frente às médias da Região Nordeste e do Brasil para o ENADE 2012, 2015 e 2018;

c) Aferir o total da população, alunos presentes e ausentes dos cursos de Direito no estado do Ceará para o ENADE 2012, 2015 e 2018;

d) Apurar a evolução da quantidade de alunos e de IES de graduação em Direito localizados na capital e no interior do estado do Ceará para o ENADE 2012, 2015 e 2018

\section{O SINAES E O ENADE}

A Constituição Federal, de 1988, traz no Capítulo III, seção I, normas pertinentes ao ensino superior e à qualidade da educação. O Artigo 207 da Carta Magna determina em seu caput: "As universidades gozam de autonomia didático-científica, administrativa e de gestão financeira e patrimonial, e obedecerão ao princípio de indissociabilidade entre ensino, pesquisa e extensão". O Artigo 209, inciso I, corrobora sobre o direito à educação superior ao definir que "Art. 209. O ensino é livre à iniciativa privada, atendidas as seguintes condições: Icumprimento das normas gerais da educação nacional". Sobre a normatização quanto à qualidade do ensino oferecido, destacam-se o Artigo 206, inciso VII, “Art. 206. O ensino será ministrado com base nos seguintes princípios: VII - garantia do padrão de qualidade". Assim como, tem-se o Artigo 208, inciso V, cuja redação determina que "Art. 208. O dever do Estado com a educação 
será efetivado mediante a garantia de: V - acesso aos níveis mais elevados do ensino, da pesquisa e da criação artística, segundo a capacidade de cada um."

A Lei de Diretrizes e Bases da Educação Nacional (LDB), Lei no 9394/96, regulamenta os preceitos constitucionais e traz diversos artigos atinentes à qualidade no ensino superior. Em seu artigo $3^{\circ}$, inciso IX 1 , ratifica que o ensino será ministrado com o objetivo de garantir um padrão de qualidade. A LDB vai além e estabelece a necessidade de implementação de processos avaliativos em todos os níveis de educação, inclusive o superior, como medida necessária à promoção da qualidade, consonante ao disposto no artigo $9^{\circ}$, incisos VI, VII, VIII, IX, a seguir transcritos:

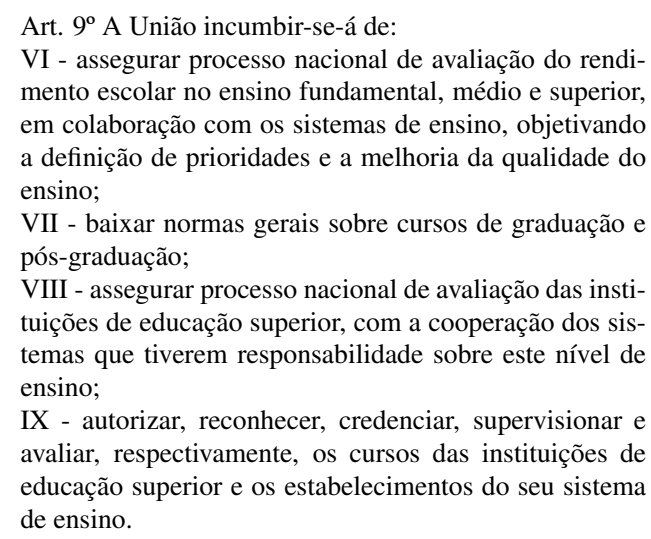

VII - baixar normas gerais sobre cursos de graduação e pós-graduação;

VIII - assegurar processo nacional de avaliação das instituições de educação superior, com a cooperação dos sistemas que tiverem responsabilidade sobre este nível de ensino;

IX - autorizar, reconhecer, credenciar, supervisionar e avaliar, respectivamente, os cursos das instituições de educação superior e os estabelecimentos do seu sistema de ensino.

Ademais, o Art. 46, caput, da LDB estabelece: "A autorização e o reconhecimento de cursos, bem como o credenciamento de instituições de educação superior terão prazos limitados, sendo renovados, periodicamente, após processo regular de avaliação”. De acordo com Leite (2006), a avaliação refere-se a "processos de construção de sentidos e conhecimentos sobre sujeitos, objetos ou coisas, atividades e instituições, colocados em relação educativa ou profissional durante determinado período de tempo". No âmbito da educação superior, a autora afirma que a avaliação "tem por objeto a supervisão e o controle do sistema de educação superior no seu conjunto e de cada uma das instituições e programas e políticas que o constituem".

O Programa de Avaliação Institucional das Universidades Brasileiras (PAIUB) foi o primeiro sistema de avaliação do ensino superior efetivamente implantado após a redemocratização do país. Entretanto, existiu por apenas um ano, durante o governo de Itamar Franco o qual ascendeu ao poder em decorrência do impeachment do presidente Fernando Collor. Segundo explicações de Fonseca (2010), apesar da pequena duração, o

\footnotetext{
${ }^{1}$ Art. $3^{\circ}$. O ensino será ministrado com base nos seguintes princípios: IX - garantia de padrão de qualidade"
}

PAIUB conseguiu grande adesão das IES, pois seu princípio basilar era a autoavaliação e a participação acadêmica. Segundo a autora, outro fator que pode ter justificado o alto índice de aceitação à época foi a não obrigatoriedade de adesão pelas IES. Conforme Barreyro e Rothen (2008), o PAIUB partia da compreensão de que avaliar é um ato político e voluntário por parte das IES e, consequentemente, uma oportunidade de cada instituição repensar seus projetos acadêmicos e sociais, buscando o autoconhecimento. Luft (2018) explica que "apesar de sua curta vigência, o PAIUB trouxe à tona discussões sobre a necessidade da autoavaliação por parte das instituições de Educação Superior".

O PAIUB foi sucedido pelo Exame Nacional de Cursos (ENEC), também conhecido como Provão, estabelecido pela Lei 9131/95, o qual vigorou do ano de 1996 a 2003. O exame era aplicado anualmente, de acordo com áreas pré-selecionadas pelo MEC. Segundo Sobrinho (2010), em 2003, último ano de aplicação, o Provão abrangeu 26 áreas de conhecimento. Ainda segundo o pesquisador, apesar de amplamente contestado em seu início, o Provão, gradualmente, consolidou-se como processo avaliatório de instituições de ensino superior, através da aplicação de provas de realização compulsória por concluintes, sob pena de retenção do diploma de graduação. "O Provão teve o mérito de colocar a avaliação na agenda da educação superior e da sociedade brasileira", (SOBRINHO, 2010).

Diante de um cenário de pós eleição do presidente Luiz Inácio Lula da Silva, em 2002, e de muitas críticas ao Provão, o Ministério da Educação instituiu o Sistema Nacional de Avaliação do Ensino Superior (SINAES), regulamentado pela Lei $\mathrm{n}^{\circ}$. 10.861, de 14 de abril de 2004, com o intuito de aprimorar a qualidade da aprendizagem nos cursos superiores. Determina o artigo $1^{\circ}$, caput e $\S 1^{\circ}$ da referida legislação:

\begin{abstract}
Art. $1^{\circ}$ Fica instituído o Sistema Nacional de Avaliação da Educação Superior - SINAES, com o objetivo de assegurar processo nacional de avaliação das instituições de educação superior, dos cursos de graduação e do desempenho acadêmico de seus estudantes, nos termos do art $9^{\circ}$, VI, VIII e IX, da Lei $n^{\circ} 9.394$, de 20 de dezembro de 1996 . $\S 1^{\circ}$ O SINAES tem por finalidades a melhoria da qualidade da educação superior, a orientação da expansão da sua oferta, o aumento permanente da sua eficácia institucional e efetividade acadêmica e social e, especialmente, a promoção do aprofundamento dos compromissos e responsabilidades sociais das instituições de educação superior, por meio da valorização de sua missão pública, da promoção dos valores democráticos, do respeito à diferença e à diversidade, da afirmação da autonomia e da identidade institucional.
\end{abstract}

Verifica-se, a partir do caput do artigo acima transcrito, que o SINAES ampliou o sistema ao contemplar a 
avaliação das IES, dos cursos de graduação e do corpo discente, baseando-se em uma visão global e integradora da educação. Polidori, Marinho-Araujo e Barreyro (2006) explicam os três eixos no SINAES. O primeiro é a Avaliação das Instituições de Educação Superior (AVALIES) realizada por meio da verificação do processo de autoavaliação executada pela Comissão Própria de Avaliação (CPA) de cada organização, somada à aferição da estrutura da instituição, constatada por avaliadores externos. A segunda vertente é a Avaliação dos Cursos de Graduação (ACG), realizada por avaliadores externos multidisciplinares, cujos resultados vinculam os processos, realizados pelo MEC, de reconhecimento e de renovação de cursos. A terceira é a Avaliação do Desempenho dos Estudantes (ENADE), aplicada no último ano dos cursos de graduação. A Comissão Nacional de Avaliação da Educação Superior (CONAES) é responsável pela administração do SINAES cuja operacionalização fica a cargo do Inep.

Conforme Sobrinho (2010), o ENADE ganhou um destaque maior do que o previsto na proposta inicial do sistema. É sabido que o exame não deve ser analisado de forma isolada. Entretanto, como explica o doutrinador, os resultados do ENADE, assim como aconteceu com o Provão, passaram a ser divulgados pelas instituições, principalmente pelas privadas, através de rankings amplamente ecoados pelas mídias publicitárias, como chancela de qualidade do ensino. O ENADE virou sinônimo de todo o sistema SINAES o que traz consequências importantes.

O ENADE é realizado todos anos, em conformidade com o ciclo avaliativo trienal, ou seja, um curso é avaliado a cada três anos. Tem como objetivo identificar o desempenho de graduandos quanto aos conteúdos programáticos das grades curriculares e aferir as habilidades dos mesmos quanto ao desenvolvimento do conhecimento e das competências próprias à profissão escolhida. O Art. $5^{\circ}, \S 6^{\circ}$ da Lei $n^{\circ} .10 .8611^{2}$ determina que a inscrição de alunos habilitados para o exame é responsabilidade da IES. Reforçando disposto em lei, o Art. $39, \S 1^{\circ}$, da Portaria Normativa $\mathrm{n}^{\mathrm{o}} 840$ do MEC, de 24 de agosto de $2018^{3}$, determina que o exame é obriga-

\footnotetext{
${ }^{2}$ Art. $5^{\circ}$ A avaliação do desempenho dos estudantes dos cursos de graduação será realizada mediante aplicação do Exame Nacional de Desempenho dos Estudantes - ENADE.

$\S 6^{\circ}$ Será responsabilidade do dirigente da instituição de educação superior a inscrição junto ao Instituto Nacional de Estudos e Pesquisas Educacionais Anísio Teixeira - INEP de todos os alunos habilitados à participação no ENADE.

${ }^{3}$ Art. 39. O Exame Nacional de Desempenho dos Estudantes Enade avaliará o desempenho dos estudantes dos cursos de graduação.

$\S 1^{\circ} \mathrm{O}$ Enade é componente curricular obrigatório, e a regularidade do estudante perante o Exame é condição necessária para a conclusão
}

tório e condição necessária para a conclusão do curso de graduação. Em consonância com Art. $5^{\circ}, \S 2^{\circ}$, da Lei $n^{\circ}$. $10.8611^{4}$ e com Art. 44 da Portaria Normativa $\mathrm{n}^{\circ} 844^{5}$, o ENADE é aplicado para os alunos de diversas graduações ao final do primeiro e do último ano do curso. Entretanto, o INEP, responsável pela implementação do SINAES, determinou a substituição da aplicação do ENADE no primeiro ano dos cursos superiores pelo Exame Nacional do Ensino Médio (ENEM).

$\mathrm{O}$ processo avaliativo do ENADE abrange quatro instrumentos de coleta de dados, em consonância com Portaria ${ }^{\circ} 840$ do MEC, Art. 41, incisos I, II, III e IV 6 Compreende a prova para aferição dos conhecimentos e competências dos concluintes; o questionário do estudante para análise do perfil socioeconômico e cultural dos acadêmicos e para identificação do ambiente de ensino-aprendizagem, da organização do curso, do currículo e da atividade docente; o questionário de percepção de prova para compreensão da impressão dos estudantes quanto à avaliação; e o questionário do coordenador do curso para identificação do perfil do coordenador do curso e dos processos formativos.

A prova, propriamente dita, avalia os estudantes em duas dimensões de conhecimentos, os componentes da formação geral e os componentes da formação específica. Segundo o Inep, a formação geral é composta

\section{do curso de graduação.}

${ }^{4}$ Art. $5^{\circ} \mathrm{A}$ avaliação do desempenho dos estudantes dos cursos de graduação será realizada mediante aplicação do Exame Nacional de Desempenho dos Estudantes - ENADE.

$\S 2^{\circ} \mathrm{O}$ ENADE será aplicado periodicamente, admitida a utilização de procedimentos amostrais, aos alunos de todos os cursos de graduação, ao final do primeiro e do último ano de curso.

${ }^{5}$ Art. 44. A avaliação promovida pelo Enade abrangerá estudantes ingressantes e concluintes de cursos de bacharelado, licenciatura e superior de tecnologia que atendam aos critérios de habilitação definidos por esta Portaria Normativa.

${ }^{6}$ Art. 41. A realização do Enade abrangerá os seguintes instrumentos de coleta de dados:

I - Prova, destinada a aferir o desempenho dos estudantes em relação aos conteúdos programáticos previstos nas diretrizes curriculares do respectivo curso de graduação, suas habilidades para ajustamento às exigências decorrentes da evolução do conhecimento e suas competências para compreender temas exteriores ao âmbito específico de sua profissão, ligados à realidade brasileira e mundial e a outras áreas do conhecimento.

II - Questionário do Estudante, destinado a levantar informações que permitam caracterizar o perfil dos estudantes e o contexto de seus processos formativos, relevantes para a compreensão dos resultados dos estudantes no Enade.

III - Questionário de Percepção de Prova, destinado a levantar informações que permitam aferir a percepção dos estudantes em relação ao instrumento previsto no inciso I, auxiliando, também, na compreensão dos resultados dos estudantes no Enade.

IV - Questionário do Coordenador de Curso, destinado a levantar informações que permitam caracterizar o perfil do coordenador de curso e o contexto dos processos formativos, auxiliando, também, na compreensão dos resultados dos estudantes no Enade. 
pelos temas: sociodiversidade, multiculturalismo e inclusão; exclusão e minorias; biodiversidade; ecologia; novos mapas sócio geopolíticos; globalização; arte e filosofia; políticas públicas; educação, habitação, saúde e segurança; redes sociais e responsabilidade; setor público, privado, terceiro setor; relações interpessoais; vida urbana e rural; inclusão/exclusão digital; cidadania; violência; terrorismo, avanços tecnológicos e relações de trabalho. No componente da formação específica, o ENADE afere o desempenho dos estudantes em relação aos conteúdos programáticos previstos nas Diretrizes Curriculares Nacionais do respectivo curso de graduação; as habilidades para ajustamento às exigências decorrentes da evolução do conhecimento; as competências para compreender temas exteriores ao âmbito específico da profissão, ligados à realidade brasileira e mundial.

A apreciação dos resultados referentes ao conceito ENADE, ao resultado geral (RG), à formação geral (FG) e ao conhecimento específico (CE) dos cursos de Direito cearenses, do total da região Nordeste e do total nacional permitirá responder aos objetivos da presente pesquisa.

\section{METODOLOGIA}

A metodologia pauta-se em uma sequência de técnicas, métodos e critérios que auxiliam na consecução dos objetivos propostos, representando caminhos ou modos para se indagar as abordagens teórico-práticas, segundo Martins e Théophilo (2009). O presente estudo utilizouse uma abordagem exploratória, documental e qualitativa através da compreensão de aspectos globais e específicos do tema objeto da pesquisa e dos diversos fatores relacionados. O estudo demandou uma pesquisa documental baseada em artigos científicos, documentos oficiais, em especial os Relatórios de Cursos disponibilizados pelo Inep, leis, informações em site, revistas especializadas, livros, entre outros.

As informações teóricas que consubstanciaram o tema proposto, a saber o SINAES, em especial, o ENADE, foram compiladas a partir de buscas realizadas nas plataformas Google Scholar e Scielo Brasil. As buscas apresentaram revistas especializadas, artigos científicos e informações em site pertinentes à pesquisa os quais remeteram a doutrinadores e estudiosos renomados na área.

A fonte principal de dados para construção dos resultados foi a análise dos Relatórios de Cursos disponibilizados pelo INEP, através de seu sítio eletrônico, compreendendo os relatórios dos anos de 2012, 2015 e 2018 para as IES localizadas no Ceará. Os 57 relatórios de cursos foram baixados em INEP (2018b), utilizando como filtros o ano, UF e área. No ano de 2012 foram baixados 16 relatórios. No ano de 2015 foram baixados 20 relatórios. No ano de 2015 foram baixados 21 relatórios. Os documentos foram examinados, individualmente, para posterior tabulação de resultados e análise crítica dos mesmos. O detalhamento dos 57 documentos apreciados está acima discriminado por IES e por ano, conforme Tabela 1 supratranscrita.

Ademais foram baixados e apreciados 3 Relatórios de Síntese da Área para os anos de 2012, 2015 e 2018, baixados a partir de INEP (2018a), utilizando como filtro o ano e a área, a saber Direito.

\section{RESULTADOS E CONCLUSÕES}

A partir da análise dos resultados, vários aspectos foram observados e serão detalhados a seguir. Estão divididos em três tópicos, contemplando: a análise do conceito ENADE, o desempenho do Resultado Geral (RG), Formação Geral (FG) e Conhecimento Específico (CE) e, ao final, a confrontação dos dados de população e de presença dos acadêmicos nos exames e o cotejo das informações de quantidade de alunos e de cursos por capital e interior.

\subsection{RESULTADOS CONCEITO ENADE}

A prova do ENADE é composta por dois grupos de questões: Formação Geral a qual engloba 10 indagações e Componente Específico o qual alberga 30 inquirições. O cálculo do Conceito ENADE é realizado a partir dos resultados de ambos, na proporção de $25 \%$ e $75 \%$, respectivamente. A nota máxima calculada é cinco e os valores são agrupados em faixas, cada faixa corresponde a um conceito, variando de 1 a 5, sendo 1 , o menor conceito e 5 o maior, conforme figura abaixo:

As provas do ENADE podem apresentar diversos graus de dificuldade de um ano para outro, pois utilizase a Teoria Clássica dos Itens (TCT). Portanto, o conceito Enade somente pode ser confrontado dentro de uma área e para um mesmo ano. Outras provas também aplicadas pelo Inep, como SAEB e ENEM, utilizam a Teoria de Resposta ao Item (TRI) a qual permite a comparação entre diferentes edições. Segundo Pasquali (2009), a TCT objetiva explicar o resultado final, ou seja, a soma das respostas dos itens expressa o escore total do teste. Já na TRI, o propósito é analisar cada um dos itens e identificar a probabilidade e fatores que afetam a possibilidade de acerto ou erro por cada indivíduo.

A tabulação dos Resultados dos Cursos, publicados nos anos de 2012, 2015 e 2018, permitiu identificar que nenhum curso de Direito de instituição de ensino su- 


\begin{tabular}{|c|c|c|c|c|}
\hline Relatório de Cursos das IES & Municipio & 2012 & 2015 & 2018 \\
\hline Universidade de Fortaleza & Fortaleza & $x$ & $\mathrm{x}$ & $\mathbf{x}$ \\
\hline Universidade Federal do Ceará & Fortaleza & $\mathrm{x}$ & $\mathbf{x}$ & $\mathrm{x}$ \\
\hline Universidade Federal do Ceará - 2 & Fortaleza & & $\mathrm{x}$ & $\mathbf{x}$ \\
\hline Centro Univeraitário Estáclo do Ceard & Fortaleza & $\mathbf{x}$ & $x$ & $\mathrm{x}$ \\
\hline Centro Universitário Sete de Setembro & Fortaleza & $x$ & $\mathrm{x}$ & $\mathrm{x}$ \\
\hline Faculdade Integrada da Grande Fortaleza & Fortaleza & $x$ & $\mathrm{x}$ & $x$ \\
\hline Centro Universittário Unichristus & Fortaleza & $\mathbf{x}$ & $\mathrm{x}$ & $\mathbf{x}$ \\
\hline Faculdade Cearense & Fortaleza & $x$ & $x$ & $\mathrm{x}$ \\
\hline Centro Universitário Fanor & Fortaleza & $x$ & $x$ & $\mathrm{x}$ \\
\hline Centro Universittário Farias Brito & Fortaleza & $\mathbf{x}$ & $\mathrm{x}$ & $\mathbf{x}$ \\
\hline Faculdade de Fortaleza & Fortaleza & $x$ & $x$ & $x$ \\
\hline Faculdade de Ensino e Cultura do Ceara & Fortaleza & $\mathbf{x}$ & $\mathbf{x}$ & $\mathbf{x}$ \\
\hline Faculdade Metropolitana da Grande Fortaleza & Fortaleza & $\mathbf{x}$ & $x$ & $\mathrm{x}$ \\
\hline Universidade Regional do Cariri & Crato & $x$ & $x$ & $\mathrm{x}$ \\
\hline Universidade Estadual do Vale do Acaraũ & Sobral & $\mathbf{x}$ & $\mathrm{x}$ & $\mathrm{x}$ \\
\hline Centro Universittário Católica do Ceardá & Qubada & $\mathbf{x}$ & $x$ & $x$ \\
\hline Faculdade Paraiso do Ceará & Juazeiro do Norte & $x$ & $x$ & $\mathrm{x}$ \\
\hline Faculdade Luciano Feijlo & Sobral & $\mathbf{x}$ & $\mathrm{x}$ & $\mathrm{x}$ \\
\hline Universidade Regional do Cariri & Iguatu & & $\mathrm{x}$ & $\mathrm{x}$ \\
\hline Faculdade do Vale do Jaguaribe & Aracati & & & $x$ \\
\hline Centro Universitário Doutor Leăo Sampaio & Sobral & & & $\mathrm{x}$ \\
\hline
\end{tabular}

Tabela 2: Conceito ENADE

\begin{tabular}{|c|c|}
\hline CONCEITO ENADE & VALORES \\
1 & 0,0 a 0,94 \\
2 & 0,95 a 1,94 \\
3 & 1,95 a 2,94 \\
4 & 2,95 a 3,94 \\
5 & 3,95 a 5,00 \\
\hline
\end{tabular}

perior localizada no estado do Ceará obteve conceito 1 nos anos analisados, de acordo com Tabela 3 abaixo. Em contrapartida, somente uma escola superior obteve a nota máxima 5, nos anos de 2015 e 2018, a saber, a Universidade Federal do Ceará. Dessa feita, tem-se que no ano de 2012, 18,75\% das instituições obtiveram conceito $2,43,75 \%$ conceito 3 e $37,5 \%$ conceito 4 , em um total de 16 organizações analisadas, sendo 11 situadas na capital e 5 estabelecidas em municípios do interior. No ano de 2015, 5,26\% das instituições obtiveram conceito $2,57,89 \%$ conceito $3,26,32 \%$ conceito 4 e $10,53 \%$ conceito 5 , em um total de 19 organizações investigadas, sendo 13 instaladas na metrópole e 6 estabelecidas em cidades do interior. No ano de 2018, 19,05\% das instituições obtiveram conceito $2,38,10 \%$ conceito $3,33,33 \%$ conceito 4 e $9,52 \%$ conceito 5 , em um total de 21 organizações examinadas, sendo 13 instaladas em Fortaleza e 8 estabelecidas em localidades no interior. Concluiu-se que nos três exames objeto do presente estudo houve a predominância do conceito ENADE 3, de acordo com tabela 3, abaixo pormenorizada.

\subsection{RESULTADO GERAL, FORMAÇÃO GERAL E CONHECIMENTO ESPECÍFICO}

Os Relatórios de Cursos de IES registraram desempenho de alunos no Componente Formação Geral, Componente Conhecimento Específico e Resultado Geral, abrangendo média, erro padrão da média, desvio padrão, mediana, nota mínima, nota máxima e coeficiente de assimetria. Até 2012, os valores foram divulgados por IES e o total do Brasil. A partir de 2015 foram acrescidas informações referentes ao Estado, Região, Categoria Administrativa e Organização Acadêmica. Outro ponto relevante foi a alteração quanto à unidade, IES, de análise. Antes de 2015, a unidade de análise era a combinação de área, instituição e cidade, ou seja, se a escola superior oferecesse curso na mesma área, em campi distintos de um mesmo município, a nota era consolidada. A partir de 2015, a nota passou a ser individualizada, fato que justificou apresentação de dois relatórios distintos para Universidade Federal 


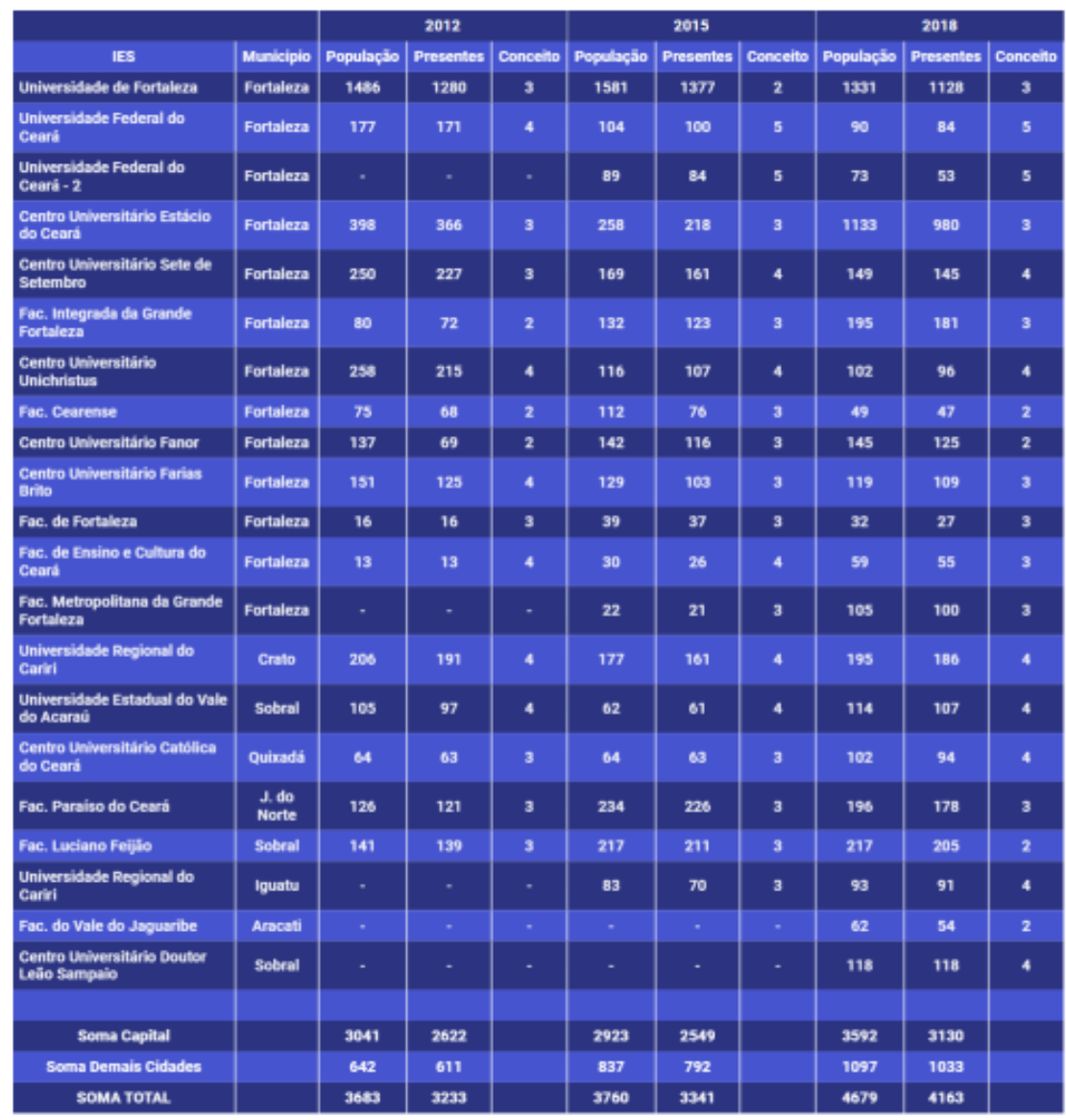

do Ceará (UFC). O presente estudo se debruçou sobre os valores das médias do Resultado Geral, Formação Geral, Conhecimento Específico (CE), por IES, Estado, Região e Brasil, consentâneo com os dados da Tabela 4

Observou-se que, nos anos analisados, $100 \%$ das IES de Direito do Ceará apresentaram média da Formação Geral superior à média do Conhecimento Específico o que demostrou que os alunos tiveram melhor desempenho nas questões de conhecimentos gerais do que nas relativas aos conteúdos programáticos específicos da área jurídica.

Quanto à média do Resultado Geral (RG), calculado a partir da Formação Geral e do Conhecimento Específico, na proporção $25 \%$ e $75 \%$, respectivamente, verificou-se que no ano de 2012 o Brasil totalizou média 40,8. Em 2015, observou-se 46,7 para o estado do Ceará, 45,5 para Região e 45,6 para o Brasil. Em 2018, verificou-se 46,3 para o estado do Ceará, 41,1 para Região e 41,5 para o Brasil. Portanto, na análise dos 3 exames objetos deste estudo, as IES cearenses de graduação de Direito obtiveram melhor desempenho na média do RG na confrontação com a Região e com o Brasil em cada exame, segundo gráfico da Figura 1 .

Figura 1: Desempenho Resultado Geral ENADE 2012, 2015 e 2018.

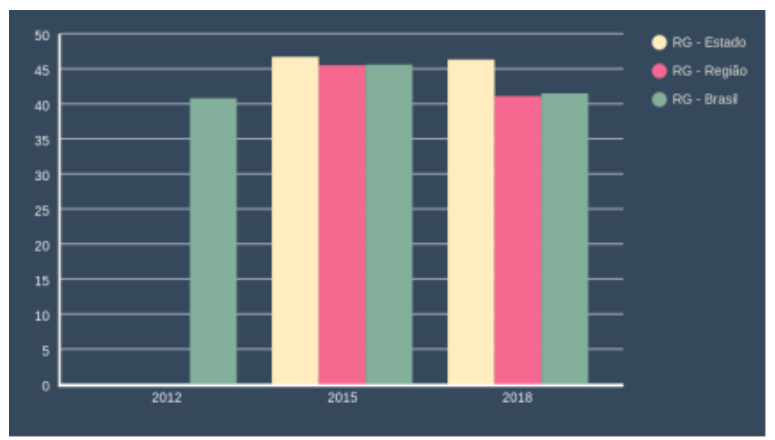

Cumpre-se esclarecer que a região compreendida no presente estudo é o Nordeste brasileiro, pois o INEP utiliza a classificação de regiões estabelecidas pelo Instituto Brasileiro de Geografia e Estatística (IBGE). Relevante também esclarecer que até o ano de 2012 não 
Tabela 4: RG, FG e CE por IES nos anos de 2012, 2015 e 2018.

\begin{tabular}{|c|c|c|c|c|c|c|c|c|c|c|}
\hline \multirow[b]{2}{*}{ IES } & \multirow{2}{*}{ Muriciplo } & \multicolumn{3}{|c|}{2012} & \multicolumn{3}{|c|}{2015} & \multicolumn{3}{|c|}{2018} \\
\hline & & RG & $\mathbf{F e}$ & $\mathbf{c e}$ & AG & FG & cE & RG & FG & CE \\
\hline Untversadade de Fortalaza & Fortaleza & 39.7 & 46.2 & 37.5 & 42.3 & 57 & 37.4 & 442 & 51.8 & 41.2 \\
\hline Unhwersidade Federal do Ceard & Fortaleza & 47 & 50.8 & 45.7 & 62.3 & 72.3 & 59 & 622 & 692 & 59.9 \\
\hline Universidade Federal do Ceard - 2 & Fortaleza & & & & 61.7 & 70.2 & 53.9 & 588 & 709 & 54.8 \\
\hline Centro Universitario Esthelo do Caurt & Fortaleza & 40.7 & 45.7 & 39 & 45.7 & 60.4 & 40.8 & 39.9 & 47.4 & 37.4 \\
\hline Centro Untwersituribo Sete de Setembre & Fortaleza & 43 & 47.7 & 41.5 & 52.4 & 61.8 & 49.3 & 50.1 & 57.8 & 47.5 \\
\hline Fac. Mnegrada da Grande Fortaleza & Fortaleza & 38.2 & 42.1 & 36.8 & 46 & 57.2 & 423 & 41.4 & 49.8 & 38.6 \\
\hline Centro Universitário Unichristus & Fortaleza & 45.3 & 51.7 & 43.1 & 56.2 & 67.1 & 525 & 525 & 593 & 50.2 \\
\hline Fac. Cearense & Fortaleza & 35.6 & 38.9 & 34.5 & 43.1 & 56.8 & 326 & 38 & 458 & 35. \\
\hline Centro Untversitánio Fanar Wyden & Fortaleza & 38.7 & 43.6 & 37.1 & 45.7 & 60.5 & 40.8 & 302 & 46.9 & 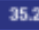 \\
\hline Centro Universitario Farias Brito & Fortaleza & 44.3 & 51.7 & 41.9 & 49 & 61.2 & 449 & 429 & 525 & 39.7 \\
\hline Fac, de Fortaleza & Fortaleza & 43.5 & 52.6 & 40.5 & 46.5 & 56.9 & 43 & 40.8 & 482.2 & 38.3 \\
\hline Fac. de Ensino e Cultura do Carát & Fortaleza & 48.4 & 60.3 & 44.4 & 52.1 & 64.4 & 48 & 39.1 & 47.7 & 36.3 \\
\hline Fac. Metropelitana da Grande Fortuleza & Fortaleza & - & - & - & 47.1 & 57.5 & 43.6 & 39.7 & 46.7 & 37.4 \\
\hline Universidade Rlogional do Cariri & Crato & 45.4 & 50.4 & 43.7 & 51.4 & 64.7 & 47 & 49.9 & 63 & 45.5 \\
\hline Universidade Estadial do Vale do Acaraú & Sobral & 48.7 & 57.3 & 45.8 & 54.1 & 65.2 & 50.4 & 486 & 60 & 448 \\
\hline Centro Universaitairio Católica do Ceara & Qubaada & 42 & 50 & 39.3 & 46.4 & 60 & 41.8 & 49.1 & 549 & 47.1 \\
\hline Fac. Paraíro do Ceard & L do Norte & 44.1 & 51.4 & 41.6 & 48.2 & 58.2 & 449 & 40.7 & 47 & 38.5 \\
\hline Fac. Luciano Felliso & Sobral & 39.4 & 44.8 & 37.6 & 46.5 & 60.6 & 41.7 & 36.6 & 45.9 & 33.5 \\
\hline Untwersidade Rlogional do Cartir & Iguatu & - & - & - & 46.1 & 60.3 & 41.3 & 46.5 & 683 & 42: \\
\hline Fac. do Vale do Jagarbe & Arsaat & - & - & - & - & - & - & 36.4 & 45 & 33.5 \\
\hline Centro Unhversititiro Doutor Lelo Sampato & Sobrat & - & - & - & - & - & - & 502 & 59.7 & 47 \\
\hline
\end{tabular}

eram disponibilizados os dados referentes ao Estado tampouco à Região.

Figura 2: Desempenho Formação Geral ENADE 2012, 2015 e 2018.

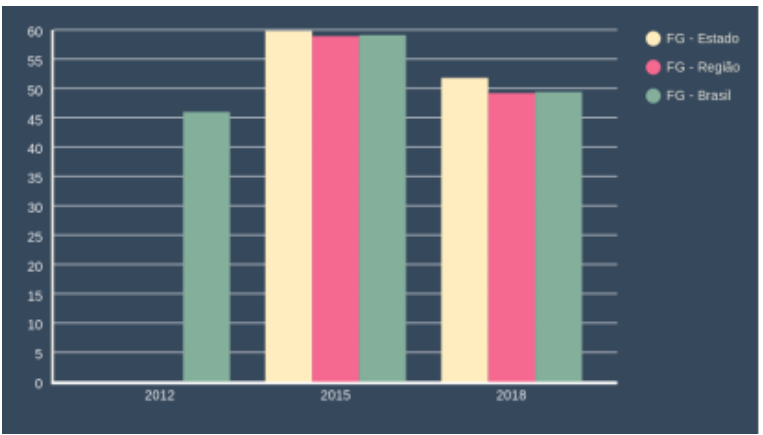

Quanto à média da Formação Geral (FG), referente ao componente de questões genéricas, transversais aos alunos da mesma área de conhecimento, verificou-se que no ano de 2012 o Brasil totalizou média 46. Em 2015, observou-se 59,8 para o estado do Ceará, 58,9 para Região e 59,1 para o Brasil. Em 2018, verificou-se 51,8 para o estado do Ceará, 49,2 para Região e 49,4 para o Brasil. No cotejo dos resultados dos 3 exames objetos do presente estudo, as IES cearenses na área jurídica obtiveram melhor desempenho na média FG frente à Região e ao Brasil, para cada ano do exame, conforme gráfico da Figura 2 .

O Conhecimento Específico (CE) compreende perguntas específicas dos conteúdos programáticos das Diretrizes Curriculares Nacionais da respectiva gradua- ção. Verificou-se que em 2012 o Brasil totalizou média 39,1. Em 2015, observou-se 42,2 para o Ceará, 41 para Região e 41,1 para o Brasil. Em 2018, verificouse 40,9 para o Ceará, 38,4 para Região e 38,9 para o Brasil. Portanto, as IES cearenses na área jurídica obtiveram melhor desempenho na média CE, comparadas com Região e o Brasil, em cada exame, conforme vislumbrado no gráfico da Figura 3

Figura 3: Desempenho Conhecimento Específico ENADE 2012, 2015 e 2018.

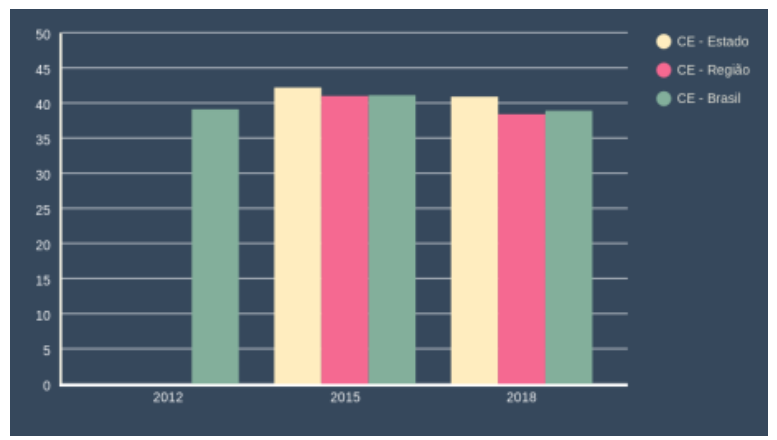

Ao comparar os resultados da RG, FG e CE obtidos para o Estado, Região e Brasil, em todas três médias o estado do Ceará esteve à frente das médias do Nordeste e do Brasil. 


\subsection{POPULAÇÃO X PRESENTES. CAPITAL X INTE- RIOR}

Os estudos permitiram observar a quantidade de alunos abrangidos pelo exame, o montante presente e o número de ausentes. No gráfico da Figura 4 os dados são detalhados:

Figura 4: População x Alunos Presentes ENADE 2012, 2015 e 2018.

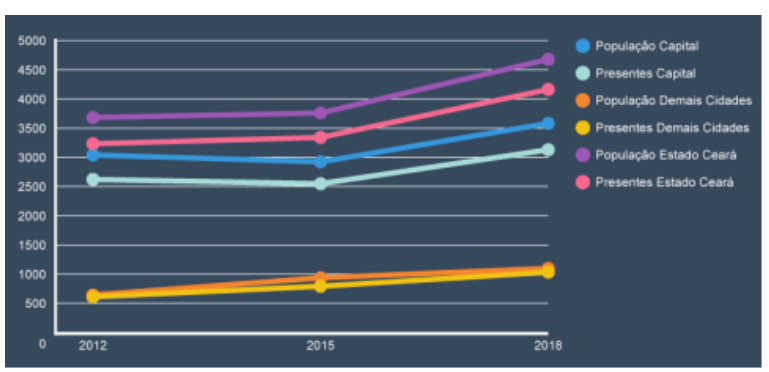

Em 2012, o ENADE inscreveu 3683 alunos concluintes dos quais 3233 realizaram o exame, totalizando 450 faltantes, ou seja, 12,22\% de abstenção. Em 2015, 3760 foram alistados dos quais 3341 efetuaram a prova, totalizando 419 ausentes, ou seja, 11,14\% de abstenção. Em 2018, 4679 foram inscritos dos quais 4163 realizaram o exame, totalizando 516 faltantes, ou seja, 11,02\% de abstenção. O percentual de faltosos variou entre $11 \%$ e $12 \%$ para cursos jurídicos do Ceará, mantendo-se estável durante os três últimos exames.

A análise permitiu constatar aumento significativo da quantidade de alunos de 2015 para 2018. O acréscimo decorreu de dois aspectos. Houve aumento considerável de alunos pelo Centro Universitário Estácio do Ceará, em consentâneo com dados apresentados na Tabela 3. Em 2015, a instituição inscreveu 258 acadêmicos dos quais 218 participaram do exame. Em 2018, foram 1133 graduandos dos quais 980 participaram da prova, ou seja, aumento aproximado de $440 \%$ nos inscritos e de $450 \%$ nos presentes. O segundo aspecto foi o incremento no número de cursos avaliados, como também visualizado na Tabela 3. Em 2015, 19 cursos foram apreciados. Em 2018, foram 21 graduações em Direito.

Outrossim, há de se destacar predominância de alunos e cursos na capital, conforme perquirição do gráfico 4. Em 2012, Fortaleza totalizava 3041 alunos, em detrimento de 642 situados no interior, na proporção de $82,57 \%$ e 11,43\%. Em 2015, Fortaleza somava 2923 alunos, em detrimento de 837 estabelecidos no interior, na proporção de $77,98 \%$ e $22,02 \%$. Em 2018, a cidade alencarina perfizera 3582 acadêmicos, contra 1097 no interior, na proporção de $76,55 \%$ e $23,45 \%$. Comparadas porcentagens de 2012, 2015 e 2018, nota-se a tendência, importante, no aumento de alunos presentes em cidades interioranas. Esta inclinação é confirmada na verificação do incremento de escolas superiores situadas fora da capital, como visualizado na Tabela $3 \mathrm{Em}$ 2012, tinha-se 11 unidades em Fortaleza e 5 no interior, na dimensão de $68,75 \%$ e $31,25 \%$. Em 2015, somavase 12 unidades em Fortaleza e 6 no interior, na dimensão de 66,66\% e 33,33\%. Em 2018, tinha-se 12 unidades em Fortaleza e 8 no interior, na dimensão de $60 \%$ e $40 \%$. No ano de 2012, participaram 5 IES localizadas em cidades diversas da metrópole, a saber: Crato (1), Sobral (2), Quixadá (1), Juazeiro do Norte (1). Em 2015, houve adição de uma universidade em Iguatu. Em 2018, houve duas novas instituições, totalizando 8 IES participantes, assim distribuídas: Crato (1), Sobral (3), Quixadá (1), Juazeiro do Norte (1), Iguatu (1) e Aracati (1).

O cotejo dos percentuais indicou aumento gradual de IES no interior cearense, em importante e salutar movimento de expansão da oferta de cursos de graduação em Direito, mantendo os alunos próximos de suas famílias, reduzindo a migração para capital para a formação jurídica. Também se concluiu pela tendência, que se iniciou ainda nos idos na década de 90, do aumento da quantidade de alunos e de cursos de graduação de Direito em todo Brasil, inclinação que acontece no estado do Ceará na contemporaneidade.

\section{CONSIDERAÇÕES FINAIS}

O presente estudo teve como objetivo apresentar os resultados da Avaliação do Desempenho dos Estudantes (ENADE), parte da política pública de avaliação do ensino superior, SINAES, nos anos de 2012, 2015 e 2018 para os cursos de Direito do Ceará. Realizou-se análise dos resultados cearenses em relação à região Nordeste e ao acumulado nacional. Resultados discutidos no presente estudo foram obtidos a partir da consolidação dos Relatórios de Cursos publicados pelo INEP, através do sítio eletrônico do instituto.

A tabulação dos Resultados de Cursos dos anos de 2012, 2015 e 2018 identificou que nenhum curso de Direito ofertado no Ceará obteve conceito 1 nos anos analisados. Em contrapartida, somente a Universidade Federal do Ceará obteve a nota máxima 5 nos anos de 2015 e 2018. Concluiu-se que nos três exames estudados houve a predominância do conceito ENADE 3. O cotejo do desempenho discente no Componente de Formação Geral (FG) e no Componente de Conhecimento Específico (CE), identificou que, nos anos analisados, $100 \%$ das IES na área jurídica do Ceará apresentaram média FG superior à $\mathrm{CE}$. Ademais, ao escrutinar os resultados da RG, FG e CE, em todas três médias o Ceará esteve à frente do Nordeste e do Brasil. Os estudos 
OS RESULTADOS DO ENADE 2012, 2015 E 2018 PARA OS CURSOS DE DIREITO SITUADOS NO ESTADO DO CEARÁ

permitiram observar a quantidade de alunos abrangidos pelo exame, o montante presente à prova e o número de ausentes. O percentual de alunos faltosos variou entre $11 \%$ e $12 \%$, mantendo-se estável durante os três exames.

A análise crítica das informações também constatou o aumento significativo da quantidade de alunos do ano de 2015 para 2018 devido ao aumento considerável de alunos inscritos pelo Centro Universitário Estácio do Ceará, o qual apresentou um aumento aproximado de $440 \%$, como também, pelo incremento do número de IES integrantes do exame. Entre os anos de 2012 e 2018, a quantidade de IES participantes aumentou de 16 para 21 escolas superiores. Destaque-se a predominância de alunos e de cursos na capital do estado. Mas, na comparação das porcentagens de alunos e cursos nos anos analisados, notou-se a tendência, importante, no aumento de alunos presentes em cidades interioranas e a verificação do incremento de IES localizadas no interior, em um movimento, salutar, de expansão da oferta de cursos de Direito para alunos residentes fora da capital.

O presente estudo tem como limitações o estudo exclusivo do desempenho do conceito ENADE, Resultado Geral, Formação Geral e Conhecimento Específico. Foram desconsiderados os demais instrumentos de coleta de dados, compostos pelo questionário do estudante para análise do perfil socioeconômico e cultural, o questionário de percepção da prova pelos estudantes e o questionário do coordenador do curso. Desta feita, sugere-se como estudo futuro a análise dos instrumentos acima citados, os três de extrema relevância, cuja observação permitirá a melhor compreensão dos desempenhos observados quanto aos conhecimentos e competências dos concluintes, através do cruzamento destas informações com aquelas, ou seja, a junção de dados quantitativos com dados qualitativos.

\section{REFERÊNCIAS}

BARREYRO, G. B. Evaluación de la educación superior brasileña: el sinaes. Revista de la educación superior, Asociación Nacional de Universidades e Instituciones de Educación Superior, v. 35, n. 137, p. 63-73, 2006.

BARREYRO, G. B.; ROTHEN, J. C. Para uma história da avaliação da educação superior brasileira: análise dos documentos do paru, cnres, geres e paiub. Avaliação: Revista da Avaliação da Educação Superior (Campinas), SciELO Brasil, v. 13, n. 1, p. 131-152, 2008.
BRASIL. Constituição Federal 1988. 1988.

Disponível em: <http://http://www.planalto.gov.br/ ccivil_03/_ato2004-2006/2004/lei/110.861.htm>

Acesso em: 10 mar. 2021.

Lei 10.861/94. 1994. Disponível em: <http://www.planalto.gov.br/ccivil_03/_ato2004-2006/ 2004/lei/l10.861.htm> Acesso em: 10 mar. 2021.

Portaria 840/MEC, de

24/08/2018. 2018. Disponível em: $<$ http://https://www.in.gov.br/materia/-/asset_ publisher/Kujrw0TZC2Mb/content/id/38406804/ do1-2018-08-27-portaria-normativa-n-840-de-। 24-de-agosto-de-2018-38406450> Acesso em: 10 mar. 2021.

Ministério da Educação. 2021. Disponível em: <http://portal.mec.gov.br/>. Acesso em: 10 mar. 2021.

FONSECA, M. Coleção didática e prática de ensino. In: DALBEN ÂNGELA, e. a. (Ed.). Avaliação da Educação Superior no Brasil: desenvolvimento institucional e qualidade do trabalho acadêmico em questão. Belo Horizonte: Autêntica, 2010. p. 651-668.

INEP. Instituto Nacional de Estudos e Pesquisas Educacionais. 2018. Disponível em: <http://portal.inep.gov.br/relatorios> Acesso em: 15 mar. 2021.

Instituto Nacional de Estudos e Pesquisas Educacionais. 2018. Disponível em: $<$ http://enade.inep.gov.br/enade/\#!/relatorioCursos> Acesso em: 12 abr. 2021.

LEITE, D. B. C. Enciclopédia de pedagogia universitária: glossário. In: MOROSINI, M. C. (Ed.). Avaliação da Educação Superior. Brasília: INEP/MEC, 2006. p. 459-506.

LUFT, I. C. M. Do PAIUB ao SINAES: Aproximações entre as Políticas Públicas de Avaliação da Educação Superior. Dissertação (Mestrado em Educação) - Universidade Federal da Fronteira Sul, Chapecó, 2018.

MARTINS, G. d. A.; THéOPHILO, C. R. Metodologia da investigação científica para Ciências Sociais Aplicadas. 2. ed. São Paulo: Atlas, 2009.

PASQUALI, L. Psychometrics. Revista da Escola de Enfermagem da USP, SciELO Brasil, v. 43, n. especial, p. 992-999, 2009. 
POLIDORI, M. M.; MARINHO-ARAUJO, C. M.;

BARREYRO, G. B. Sinaes: perspectivas e desafios

na avaliação da educação superior brasileira. Revista

Ensaio: Avaliação e políticas públicas em Educação,

SciELO Brasil, v. 14, n. 53, p. 425-436, 2006.

SILVA, A. L. d.; GOMES, A. M. Avaliação

institucional no contexto do sinaes: a cpa em questão.

Avaliação: Revista da Avaliação da Educação

Superior (Campinas), SciELO Brasil, v. 16, n. 3, p. 573-601, 2011.

SOBRINHO, J. D. Avaliação e transformações da educação superior brasileira (1995-2009): do provão ao sinaes. Avaliação: Revista Da Avaliação Da Educação Superior (Campinas), SciELO Brasil, v. 15, n. 1, p. 195-224, 2010. 